\title{
Multicentric Reticulohistiocytosis - A Rare Clinicopathological Entity
}

\author{
Bhuvitha M. S. ${ }^{1}$, Nandakumar G. ${ }^{2}$ \\ 1, 2 Department of Pathology, Government Medical College, Trivandrum, Kerala, India.
}

\section{INTRODUCTION}

This is a rare case report of a thirty-eight-year-old male who presented with multiple asymptomatic hyper-pigmented papulonodular lesions on the face for the past two years without the association of pain or pruritus and with restriction of elbow movements. The diagnosis of multicentric reticulohistiocytosis was made on histopathological findings of Touton type of giant cells and sheets of foamy histiocytes along with immunohistochemistry (IHC) studies. Workup was done for other associated diseases.

Multicentric reticulohistiocytosis (MRH) is also known as lipoid dermatitis, ${ }^{1}$ a rare disease which is characterised by the presence of extensive papulonodular cutaneous eruptions and severe, sometimes destructive arthropathy, followed by eruption of the skin and mucous membrane lesion. ${ }^{2,3}$ It's a rare idiopathic nonLangerhans cell histiocytosis. ${ }^{4}$ This disorder is characterised by predominant cutaneous manifestation and joint involvements. The lesions may show regression and recurrence, many case studies show an association of this lesion with internal malignancies, autoimmune diseases, hyperlipidaemias, and tuberculosis. ${ }^{5,6} \mathrm{Few}$ cases have shown musculoskeletal involvement with features such as myositis.

The disease was described initially as reticulocytosis granuloma in 1952 by Caro and Senear, later the term was coined by Goltz and Laymon as multicentric reticulohistiocytosis in $1954 .{ }^{4}$ It is also known by different names such as giant cell histiocytosis, lipoid dermato-arthritis, lipoid-rheumatism and reticulohistiocytosis granuloma. The disease incidence is very low worldwide, less than 200 cases have been reported in literature ${ }^{5}$ and reports from India are limited.

\author{
Corresponding Author: \\ Dr Bhuvitha M. S., \\ Department of Pathology, \\ Government Medical College, \\ Trivandrum, Kerala, India. \\ E-mail: msbhuvitha1993@gmail.com
}

DOI: $10.14260 / j e m d s / 2021 / 581$

How to Cite This Article:

Bhuvitha MS, Nandakumar G.. Multicentric reticulohistiocytosis: a rare clinicopathological entity. J Evolution Med Dent Sci 2021;10(33):2854-2857, DOI: $10.14260 /$ jemds $/ 2021 / 581$

Submission 14-03-2021,

Peer Review 14-06-2021,

Acceptance 19-06-2021,

Published 16-08-2021.

Copyright (c) 2021 Bhuvitha M.S. et al. This is an open access article distributed under Creative Commons Attribution License [Attribution 4.0 International (CC BY 4.0)] 


\section{PRESENTATION OF CASE}

A 38-year-old male patient presented to the outpatient department with multiple asymptomatic hyper-pigmented papulonodular lesions of two years duration, below the eyes which gradually increased in size. There was no association of pain or pruritus. The patient also had complaints of left elbow pain with restricted movements, history of small, raised skincoloured lesions over the lower back. There was no history of weight loss or loss of appetite, and the patient was stable without any other complaints.

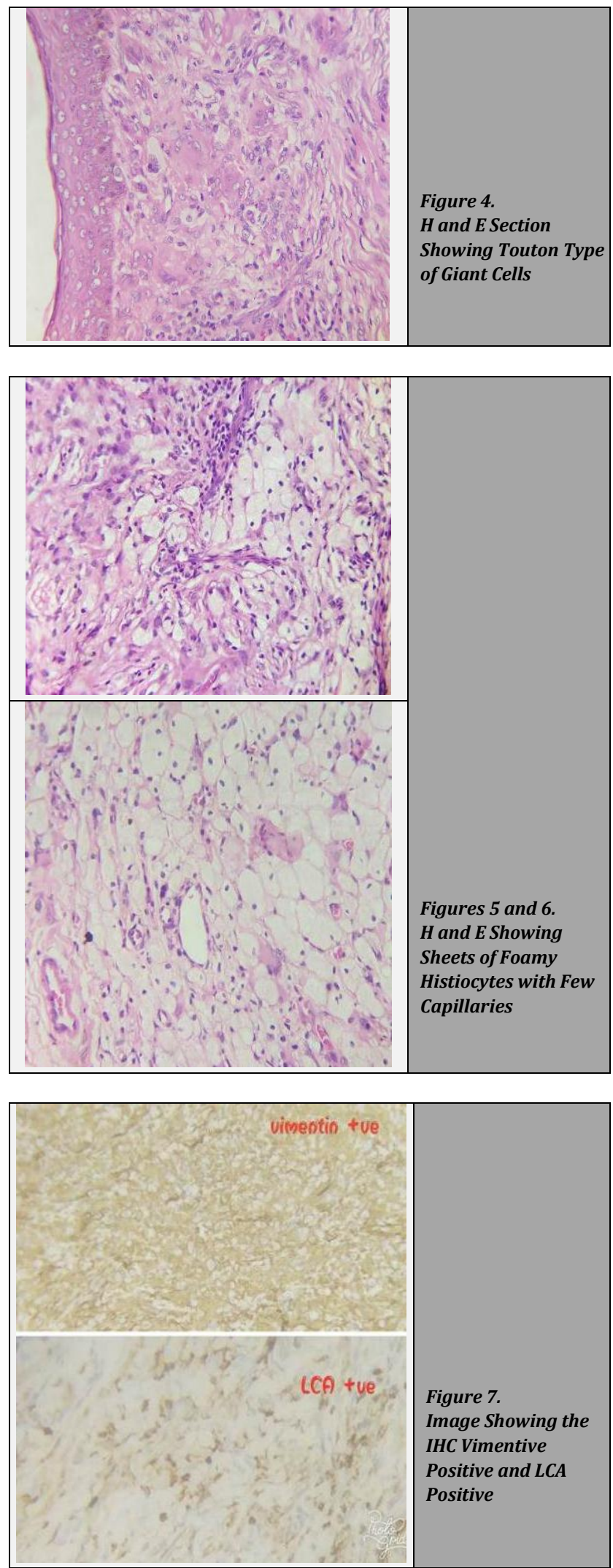

Clinical examination of the patient, revealed multiple discrete, confluent papule, confluent plaques, nodules predominantly with soft firm and hard areas over eyelids extending to the forehead (figure 1), inferiorly to cheeks and medially to nose involving nasolabial fold, upper lip, lower lip and chin (figure 2). X-ray of the left elbow showed a lytic lesion in the trochlear area (figure 3). Routine blood investigations did not reveal any significant abnormality. 
Histopathology of skin lesions showed a good number of Touton type of multinucleated giant cells (400x, Figure 4), sheets of foamy histiocytes (400x, Figure 5 \& 6) and, immunohistochemical studies showed the cells to be positive for vimentin and LCA (400x, Figure 7), S100 and CD1a were found to be negative.

\section{DISCUSSION}

The exact etiopathogenesis of the condition is not understood, although with available literature it is believed to be, due to the increased levels of inflammatory cytokines like TNF- $\alpha$, IL-1, 6 and 12 by unregulated activation by macrophages. ${ }^{2}$ The cardinal symptoms of this condition are mainly those of joint and skin. ${ }^{7}$ Studies show that it can be present in $45 \%$ of the patients as a sole symptom, skin symptoms manifest in $30 \%$ of patients. ${ }^{7}$ Inflammatory joint disease is usually a frequent presenting symptom. Arthropathy usually precedes skin lesions in $50 \%$, skin lesions may precede in $25 \%$ cases or both concurrently in $25 \%{ }^{1}$

The joint manifestations include diffuse symmetric, progressive, and destructive polyarthritis affecting interphalangeal joints mainly distal interphalangeal joints in $75 \%$, followed by other joints like knees, wrists, shoulder, and elbows. This may progress to debilitating arthritis mutilans. ${ }^{3,8}$ In females, it most commonly presents in the fifth or sixth decade with symmetrical polyarthritis which progresses to destructive arthropathy. And two other studies by, Conaghan et al. and Tsubamoto et al. have studied the MRH with symptoms of pre-eclampsia. ${ }^{9}$

Involvement of the interphalangeal joints result in a shortening and telescoping of digits known as the "opera-glass hand." This may also present as other forms of arthritis, such as psoriatic and rheumatoid arthritis, but MRH has the potential to turn into the most rapidly destructive forms of arthritis. $^{10}$ MRH synovial fluid contains numerous macrophages that are capable of differentiating into osteoclasts by the RANKL signalling pathway. ${ }^{11}$ Cutaneous manifestation usually presents as multiple erythematous to brown papulonodular lesions which may coalesce to form plaques mainly seen over ears, nose, dorsal aspect of hands and trunk. The appearance of papules in the periungual region is described as "Coral beads". 8 Constitutional symptoms like fever, malaise, weakness, weight loss, anorexia may be present, and disease can involve multiple organ systems including cardiac and skeletal muscle, pleura and gastrointestinal system.6,12

This condition may show features of rheumatoid arthritis and dermatomyositis. Millar et al. reported a suspected case with rheumatoid arthritis, weakly positive for rheumatoid factor, presenting with skin nodules which proved to be MRH on histopathology and further investigations showed association with metastatic large cell carcinoma. ${ }^{13}$ Other differential diagnoses for this condition include histiocytosis $\mathrm{X}$, familial histiocytic dermato-arthritis, lepromatous leprosy, adult xanthogranuloma, sarcoidosis, xanthogranulomatosis, generalised eruptive histiocytoma and neuro-fibromatosis. ${ }^{14}$

No evidence of involvement of any causative infectious organism is reported in its etiopathogenesis. ${ }^{15}$ Hyperlipidaemia is reported in $10-20 \%$ of cases. ${ }^{15}$
Association with autoimmune disease has been found in 5 - 20 $\%$ cases $^{8}$ which includes Sjogren's syndrome, coeliac disease, primary biliary cirrhosis, systemic sclerosis, systemic lupus erythematosus, myopathy, diabetes mellitus and hypothyroidism.6,8

Xanthelasma and hypercholesterolaemia were recorded in $30 \%$ of patients with multicentric reticulohistiocytosis. ${ }^{16}$ Even though there are various assumptions regarding the paraneoplastic phenomenon, associations have been reported with malignancies (approximately 25 - $30 \%$ ) like carcinoma of breast, cervix, ovary, stomach, colon, lung, bronchus, melanoma, lymphoma, leukaemia, and sarcoma. ${ }^{5}$ Also a case of thymic carcinoma associated with MRH has been reported. ${ }^{17}$

Laboratory investigations frequently show an elevated level of C-reactive protein, erythrocyte sedimentation rate and hyperlipidaemia., Radiologic findings include erosion of joints which are initially circumscribed and later spread from margins to involve entire joint surface, widening of joint space, loss of cartilage and resorption of subchondral bone. ${ }^{15}$ Histological and immunological studies form the main diagnostic features of MRH. Infiltration of the dermis with mononuclear and multinucleated giant cells with eosinophilic "Ground Glass" PAS-positive cytoplasm is typical of MRH. ${ }^{17}$ Infiltrating cells show positivity for CD 68, lysosome, TRAP, and human alveolar macrophage -56 (HAM), negative for S100, CD1a and factor XIIIa. ${ }^{1}$ and for LCA and Vimentin.

Prognosis and clinical course are unpredictable, and disease may recur spontaneously. If not treated it will lead to debilitating arthropathy and cutaneous scarring. ${ }^{6}$ No definite guidelines for the treatment of this condition, exists. Recent studies with TNF antagonists have shown usefulness in inducing remission and allowing in reduction of steroid dosage in refractory cases of MRH. ${ }^{15}$

Thus, from the above investigations, the present case is being reported for its rarity and striking clinical and histopathological features.

Financial or other competing interests: None.

Disclosure forms provided by the authors are available with the full text of this article at jemds.com.

\section{REFERENCES}

[1] Shah SP, Shah AM, Prajapati SM, et al. Multicentric reticulohistocytosis. Indian Dermatol Online J 2011;2(2):85-7.

[2] Tran TH, Pope E, Weitzman S. Cutaneous Histiocytosis. In: Text book of Dermatology. 9th edn. John Wiley Publishers 2016:136.

[3] Saba R, Kwatra SG, Upadhyay B, et al. Multicentric reticulohisticytosis presenting with papulonodular skin lesions and arthritis mutilans. Case Rep Rheumatol 2013;2013:201563.

[4] Rezaieyazdi Z, Sandooghi M, Torghabe HM, et al. Multicentric reticulohistiocytosis: a case report. Acta Med Iran 2005;43:372-6.

[5] Mukherjee S, Gangopadhyay DN. Multicentric reticulohisticytosis: a rare case report. Indian Dermatol 2012;57(4):302-3. 
[6] Koh CC, Jong KK. Reticulohistiocytosis: a case series in Hong Kong. Hong Kong J Dermatol Venereol 2012;20:511.

[7] Haridas V, Haridas K. Multicentric reticulohistiocytosis. J Case Rep 2015;5:160-2.

[8] Cheng L, Chiang Y. Multicentric reticulohidtiocytosis in a Taiwanese woman with sjogren syndrome. Dermatol Sinica 2016;34(1):42-5.

[9] Brackenridge A, Bashir T, Wheatley T. Multicentric reticulohistiocytosis and pregnancy. BJOG 2005;112(5):672-3.

[10] Rapini RP. Multicentric reticulohistiocytosis. Clin Dermatol 1993;11(1):107-11.

[11] Adamopoulos IE, Wordsworth PB, James RE. Osteoclast differentiation and bone resorption in multicentric reticulohistiocytosis. Hum Pathol 2006;37(9):1176-85.

[12] Campbell DA, Edwards NL. Multicentric reticulohistiocytosis: systemic macrophage disorder. Baillieres Clin Rhematol 1991;5(2):301-9.
[13] Millar A, Kane D0, Taggart A. Multicentric reticulohistiocytosis: a lesson in screening for malignancy. Rheumatol 2008;47(7):1103-4.

[14] Yap FBB. Multicentric reticulohistiocytosis in a Malaysian Chinese lady: a case report and review of literature. Dermatol Online J 2009;15(1):2.

[15] Kuntoji V, Kudligi C, Bhagwat PV, et al. Multicentric reticulocytosis: a case report with review. Our Dermatol 2017;8:302-5.

[16] Lambert CM, Nuki G. Multicentric reticulohistiocytosis with arthritis and cardiac infiltration: regression following treatment for underlying malignancy. Ann Rheum Dis 1992;51(6):815-7.

[17] Rudha Y, Starobinska E, Abdulqader Y, et al. Multicentric reticulohistiocytosis associated with thymic carcinoma. Rheumatology (Oxford) 2017;56(10):1706. 